\title{
PERFORMANCE ANALYSIS OF IC ENGINE USING SUPERCHARGER AND TURBOCHARGER-A REVIEW
}

\author{
Prashant.N.Pakale ${ }^{1}$, S.U.Patel ${ }^{2}$ \\ ${ }^{I}$ PG Student, Mechanical Engineering Department, D.N.Patel COE shahada, Maharashtra, India \\ ${ }^{2}$ H.O.D, Mechanical Engineering Department, D.N.Patel COE shahada, Maharashtra, India
}

\begin{abstract}
There are many inventions aimed at increasing the performance of IC engines. So most engines nowdays are employed with turbocharger and supercharger. It is known that the power outputs of an engine increases with the increase in amount of air or mixture in the cylinder and supercharger plays an important role in increasing the amount or air. Turbochargers are used throughout the automotive industry as they can enhance the output of an internal combustion (IC) engine without the need to increase its cylinder capacity. The emphasis today is to provide a feasible engineering solution to manufacturing economics and "Greener" road vehicles. It is because of these reasons that superchargers and turbochargers are now becoming more and more popular in automobile applications. The aim of this paper is to provide a review on the techniques used in supercharging and turbocharging to increase the engine output and reduce the exhaust emission levels.
\end{abstract}

Keywords: IC Engine, Supercharger, Turbocharger.

$* * *$

\section{INTRODUCTION}

\subsection{Other Methods for Improvement of}

\section{Performance of an Engine:}

1. Increasing speed of the engine,

2. Use of higher compression ratio,

3. Utilization of exhaust gas energy,

4. Use of two stroke cycle.

5. Improving volumetric efficiency of the engine,

6. Increasing the charge density.

\section{INTRODUCTION TO SUPERCHARGING}

It is known fact that the power output of an engine increases with an increase in amount of air or mixture in the cylinder at the beginning of compression stroke because it allows the burning of more quantity of fuel. The amount of air induced per unit time can be increased by increasing engine speed or increasing air density during suction stroke. The increase in engine speed requires rigid and robust engine as the inertia load increases rapidly with an increases speed. The engine friction and bearing loads also increase and volumetric efficiency falls with increasing speed of engine. Therefore this is not possible. Now another method in which we have to increase the suction pressure is called supercharging. Equipment used for this is called Supercharger.

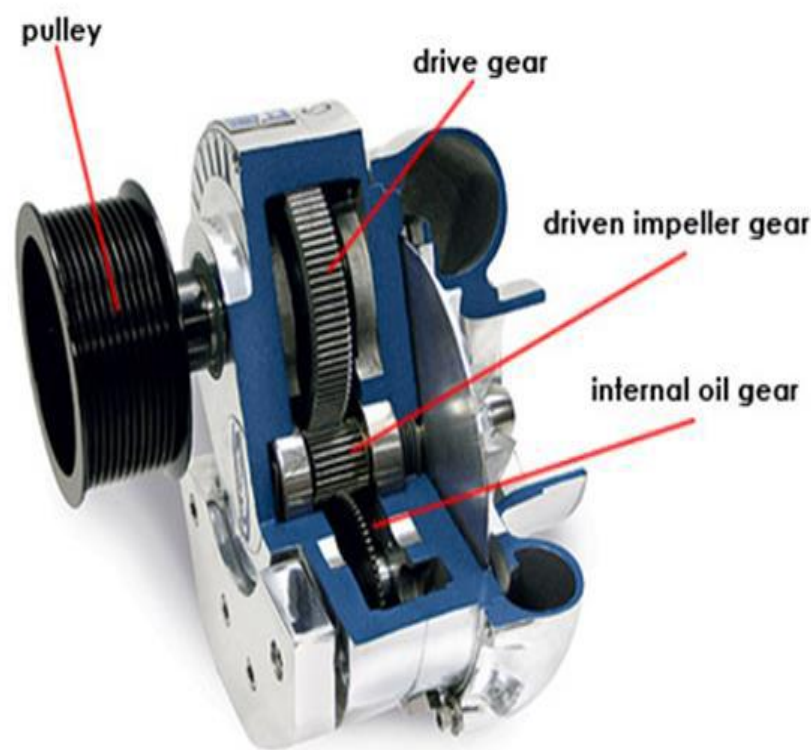

Fig -1: Supercharger

\subsection{Objective of Supercharging}

Supercharging is a process which helps to increase the suction pressure of I.C. Engines above the atm. pressure. The main object of supercharging is to increase the air charge per cycle and permit the burning of a larger amount of fuel and thus increase the power output of the engine.

It is preferred to fulfill the following requirements:

1. To overcome effect of high attitudes

2. To reduce the weight of engine per $\mathrm{kW}$

3. To reduce the size of the engine to fit into limited space

4. To increase the power of an existing when the greater power demand occurs. 


\subsection{Working of Supercharging}

The power of an aircraft engine depends on the pressure developed in its individual cylinders whilst on their working strokes. This pressure arises from the combustion of liquid fuel which has been introduced into the cylinder along with a charge of air during the induction stroke. Since it is a chemical fact that good combustion is possible only over a comparatively narrow range of mixture strengths, it follows that the amount of fuel that can be burnt per power stroke is limited by the weight of air in the cylinder. More air means more power and so the current demand for increased engine outputs is met by larger cylinders, by more of them, or by running at higher speeds to deal with a greater weight of air in unit time. With a normal (unsupercharged) engine, it is the pressure of the atmosphere which forces air through the carburetor and into the cylinders on the induction stroke. As atmospheric pressure falls with altitude, the weight of air available for combustion also falls off and power goes lower in sympathy. It was soon realized that this natural fall-off with altitude could be avoided if we could deceive the engine that it was still at sea level by blowing air into its induction system using some kind of pump. This process is "supercharging."

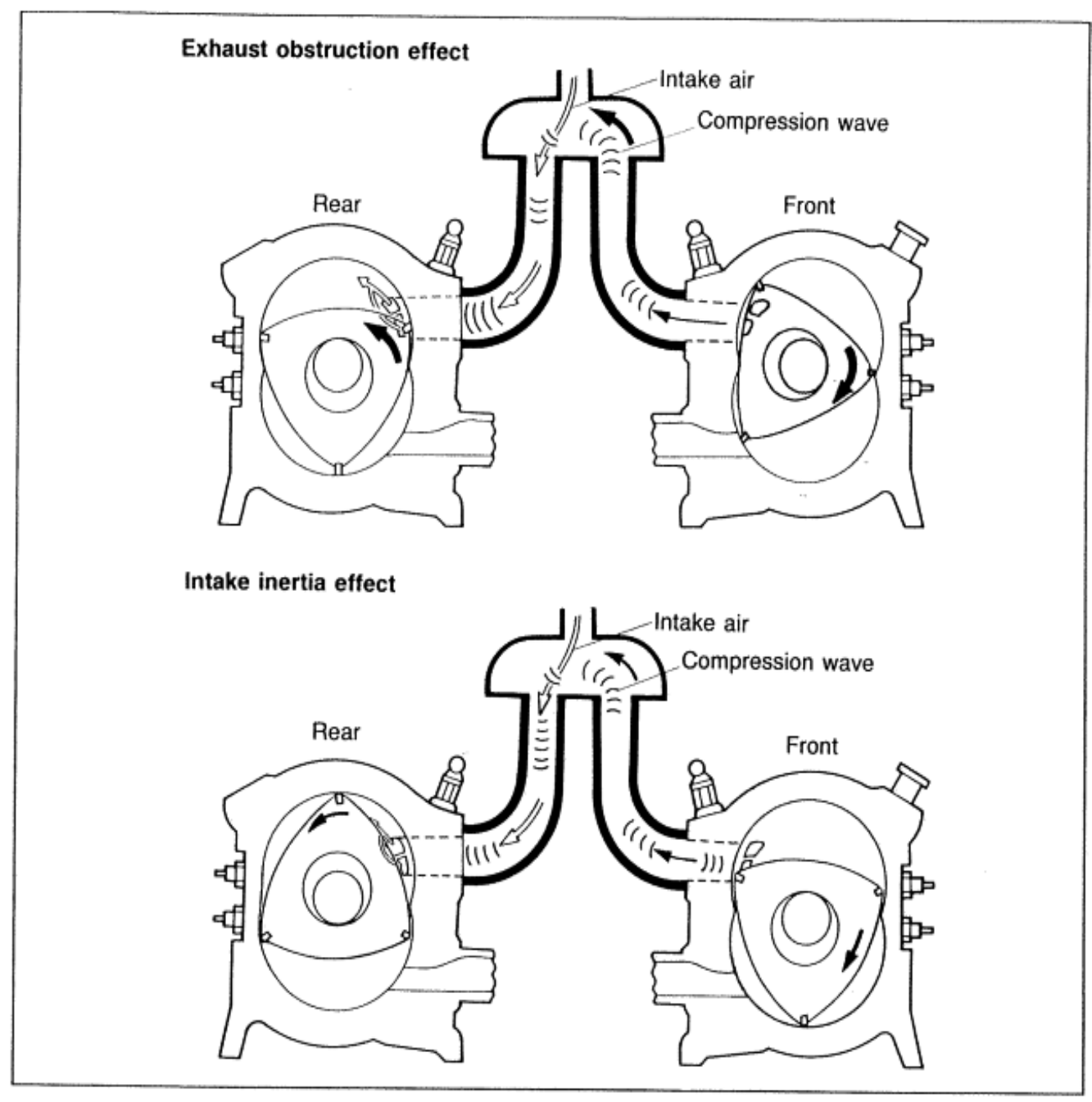

\subsection{Benefits of Supercharging}

1) Due to the lower volumetric displacement of the supercharged engine, frictional \& thermal losses are less.

2) Brake power will increase about 30-45 percent because of increase in supercharged pressure as more amount of fuel will be burnt within the same period as the mass taken per stroke is increased.

3) The power-to-weight ratio, i.e. kilowatt (power output)/kilograms (engine weight); of the supercharged engine is much better than that of the naturally aspirated engine.

4) The supercharged engine's installation space requirement is smaller than that of a naturally aspirate engine with the same power output.

5) The high altitude performance of a supercharged engine is significantly better. Because of reduced engine is smaller; it is therefore less noisy than a naturally aspirated engine with identical output.

6) It is very simple for high speed engine. 


\subsection{Limitations of Supercharging}

1) The biggest disadvantage of superchargers is also their defining characteristic: Because the crankshaft drives them, they must steal some of the engine's horsepower. A supercharger can consume as much as 20 percent of an engine's total power output.

2) Not able to guarantee maximum performance of the supercharger due to physical limitations of the system.

3) Reliability of engine decreases with increase in maximum pressure in the cylinder

4) Increase in pressure increases thermal load on engine due to increase in the rate of heat release.

\section{INTRODUCTION TO TURBOCHARGING}

BMW was the first to use turbo-charging in a production passenger car when they launched the 2002 in 1973 . The car was brilliantly packaged too and paved the way for a simply magnificent 'Turbo Era' in the automotive world. A turbocharger is a device used to allow more power to be produced for an engine of a given size. A turbocharged engine can be more powerful and efficient than a naturally aspirated engine because the turbine forces more intake air, proportionately more fuel, into the combustion chamber than if atmospheric pressure alone is used. Its purpose is to increase the volumetric efficiency of the combustion chamber. Various new technologies have been introduced to assist the turbocharging of internal combustion engine so that the volumetric efficiency may improve more. These technologies include inter-cooling of the charged air before going in to the combustion chamber so that its mass flow rate is increased. The other technology is twin charging in which firstly the engine is boosted by a supercharger then it is boosted by a turbocharger when the energy of exhaust gas is sufficient to rotate the turbine blades.

In turbocharging, the turbocharger is being driven by a gas turbine using the energy in exhaust gases. The major parts of turbocharger are turbine wheel, turbine housing, turbo shaft, comp. wheel, comp. housing \& bearing housing.

\subsection{Working of Turbocharger}

Since the power a piston engine can produce is directly dependent upon the mass of air it can ingest, the purpose of forced induction (turbo-supercharging and supercharging) is to increase the inlet manifold pressure and density so as to make the cylinders ingest a greater mass of air during each intake stroke. A supercharger is an air compressor driven directly by the engine crankshaft, and as such, consumes some of the power produced by the combustion of fuel, thereby increasing BSFC and engine wear for a given amount of produced power. A turbocharger consists of a single-stage radial-flow (-centrifugall) compressor (air pump), which is driven by a single-stage radial-flow turbine, instead of being driven directly by the crankshaft. The turbine extracts wasted kinetic and thermal energy from the high-temperature exhaust gas flow and produces the power to drive the compressor, at the cost of a slight increase in pumping losses.

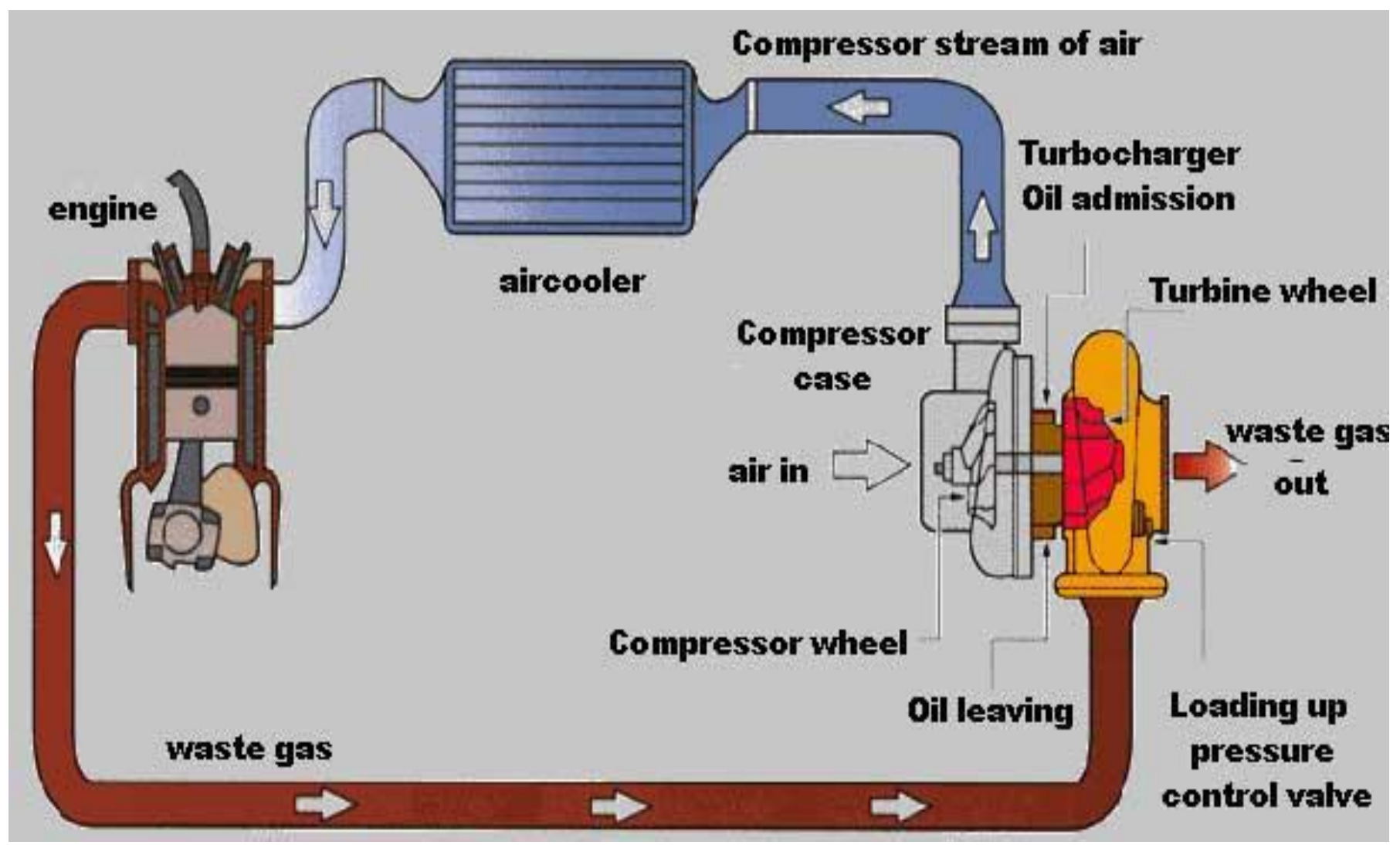




\section{COMPRESSOR SECTION}

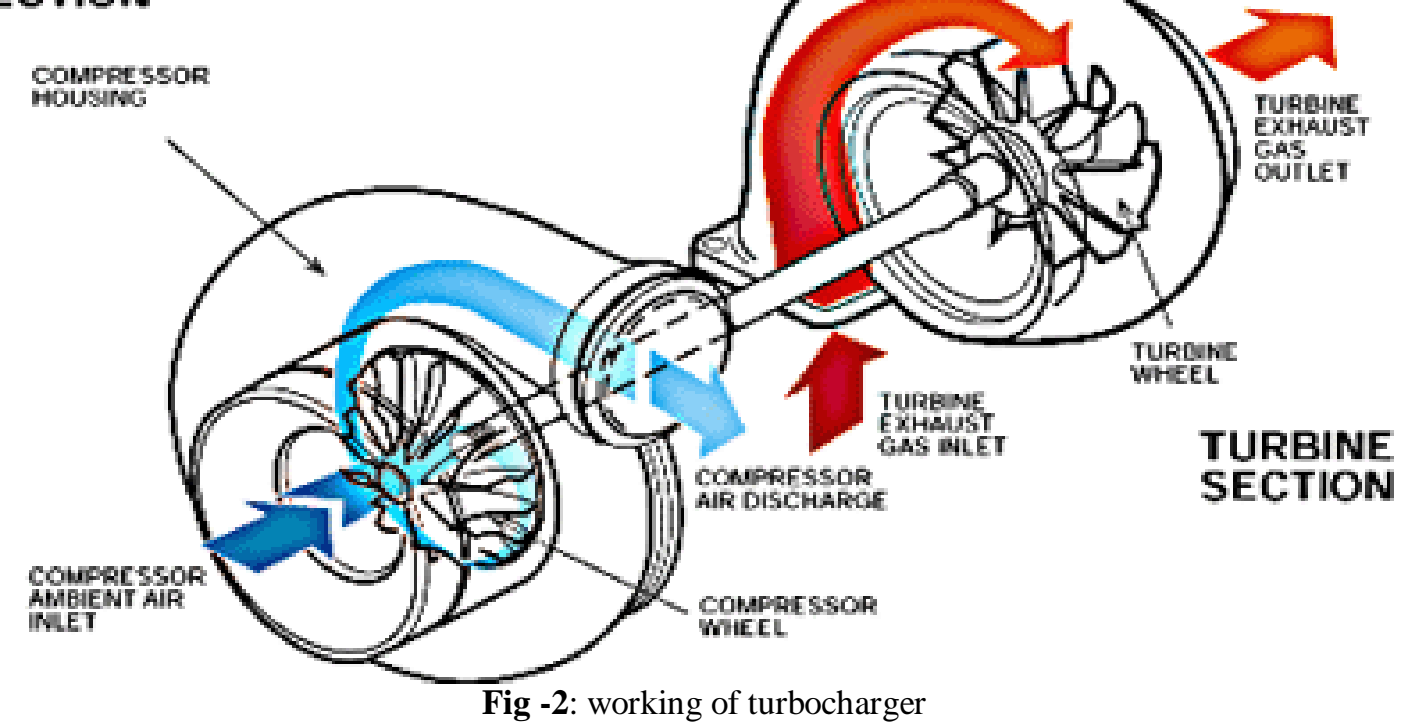

\subsection{Two-Stage Turbocharging for Four-Stroke}

\section{Engine}

The first four-stroke engines with two-stage turbocharging are on the market. At ABB, two-stage turbocharging is already entering its second generation. On diesel engines the aim is to further enhance NOx emissions, fuel consumption and power density and on gas engines power density, load acceptance and operating flexibility. Ease-of-maintenance is also a high priority.

\subsubsection{Two-Stage Turbocharging Benefits}

The first generation of ABB Turbo Systems' Power twostage turbocharging concept has been successfully applied on large four-stroke engines since 2010 [1, 2, 3]. Engine efficiency gains and emissions reduction have been demonstrated which are clearly beyond the potential of single-stage turbocharging. ABB Turbo Systems has now developed the second generation of its Power systems for large four- stroke engines, to fully realize the potentials offered by the presence of two turbocharging stages. A key driver is enabling extreme Miller Cycles on large fourstroke engines. On diesel engines, the Miller Cycle and high pressure turbocharging - in particular two-stage turbocharging - enable substantial reductions in emissions of oxides of nitrogen (NOx) while improving fuel efficiency and power density. Alternatively, highly fuel optimised designs are possible when an SCR catalyst (Selective Catalytic Reduction) is applied for subsequent treatment of the exhaust gases to reduce NOx emissions down to the required levels. The Miller Cycle in combination with high pressure turbocharging is also applicable on gas engines, where the reduction in cylinder charge temperature can be used to reduce the tendency for combustion knock and thus allow higher compression ratios/efficiencies. Key performance improvements are added to the intrinsically low NOx emissions of lean burn gas engines burning zero sulphur fuels while benefitting from actual and predicted low fuel prices. Improved engine efficiency, enhanced power density and reduced power loss at high altitude and in hot and humid ambient conditions result.

\subsection{Benefits of Turbocharging}

1) More power compared to the same size naturally aspirated engine.

2) Better thermal efficiency over naturally aspirated engine and super charged engine, because the engine exhaust is being used to do the useful work which otherwise would have been wasted.

3) Better Fuel Economy by the way of more power and torque from the same sized engine. A century of development and refinement - for the last century the SI engine has been developed and used widely in automobiles.

4) Low cost-The SI engine is the lowest cost engine because of the huge volume currently produced.

5) High Thermal efficiency.

6) Better Volumetric efficiency.

7) Continual development of this technology has produced an engine that easily meets emissions and fuel economy standards. With current computer controls and reformulated gasoline, today's engines are much more efficient and less polluting than those built 20 years ago.

8) High speed obtained.

9) Better average obtained.

10) Eco-friendly.

\subsection{Limitations of Turbocharging}

1) Engine weight will increase.

2) If there will be improper maintenance then there will be problem in turbo such as turbo lag.

3) Engine cost will increase. 


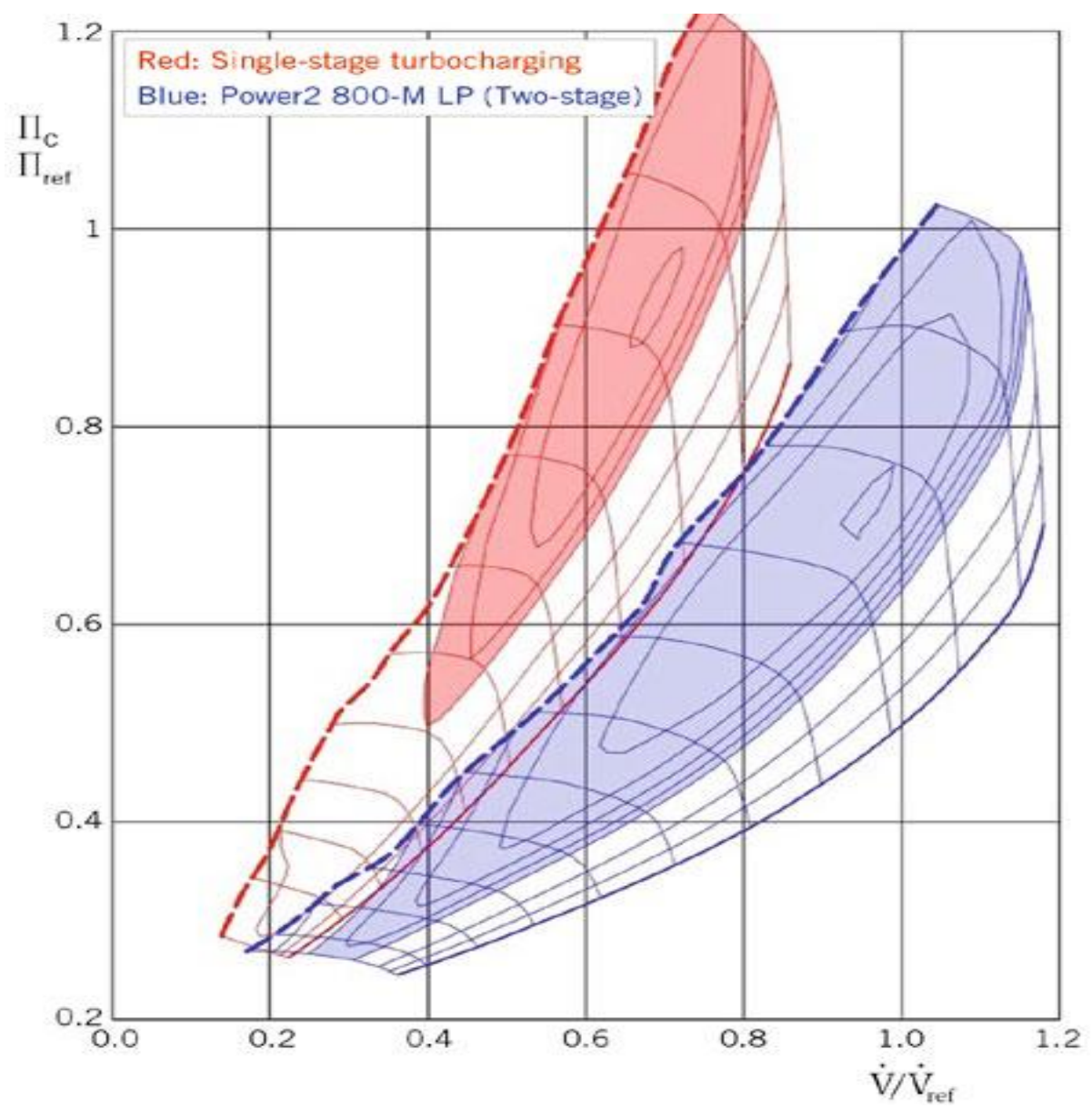

Fig -3: single and double stage low pressure turbocharging effect.

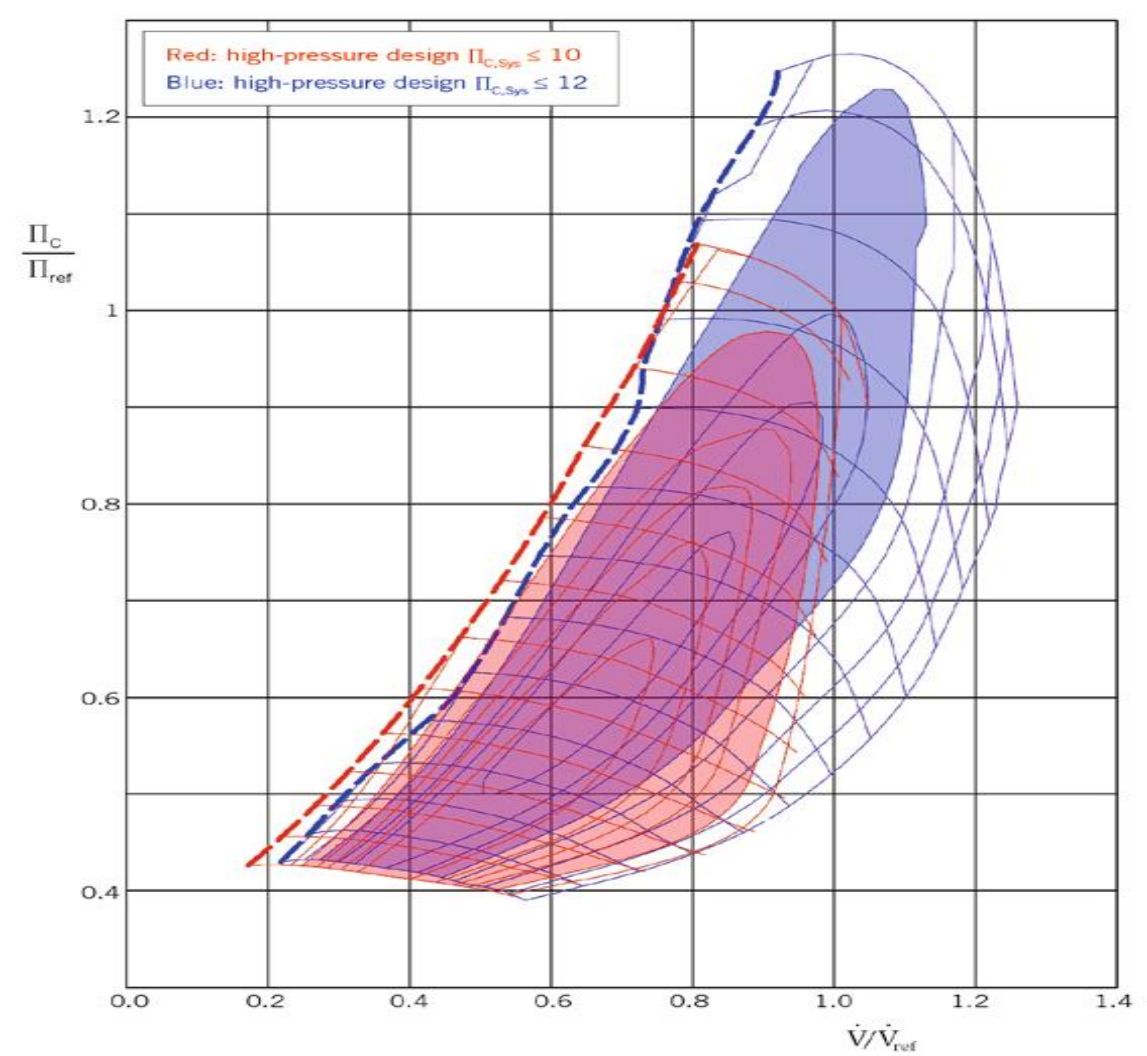

Fig -3: single and double stage high pressure turbocharging effect. 


\section{COMBINATION OF SUPERCHARGER AND TURBOCHARGER IN IC ENGINE}

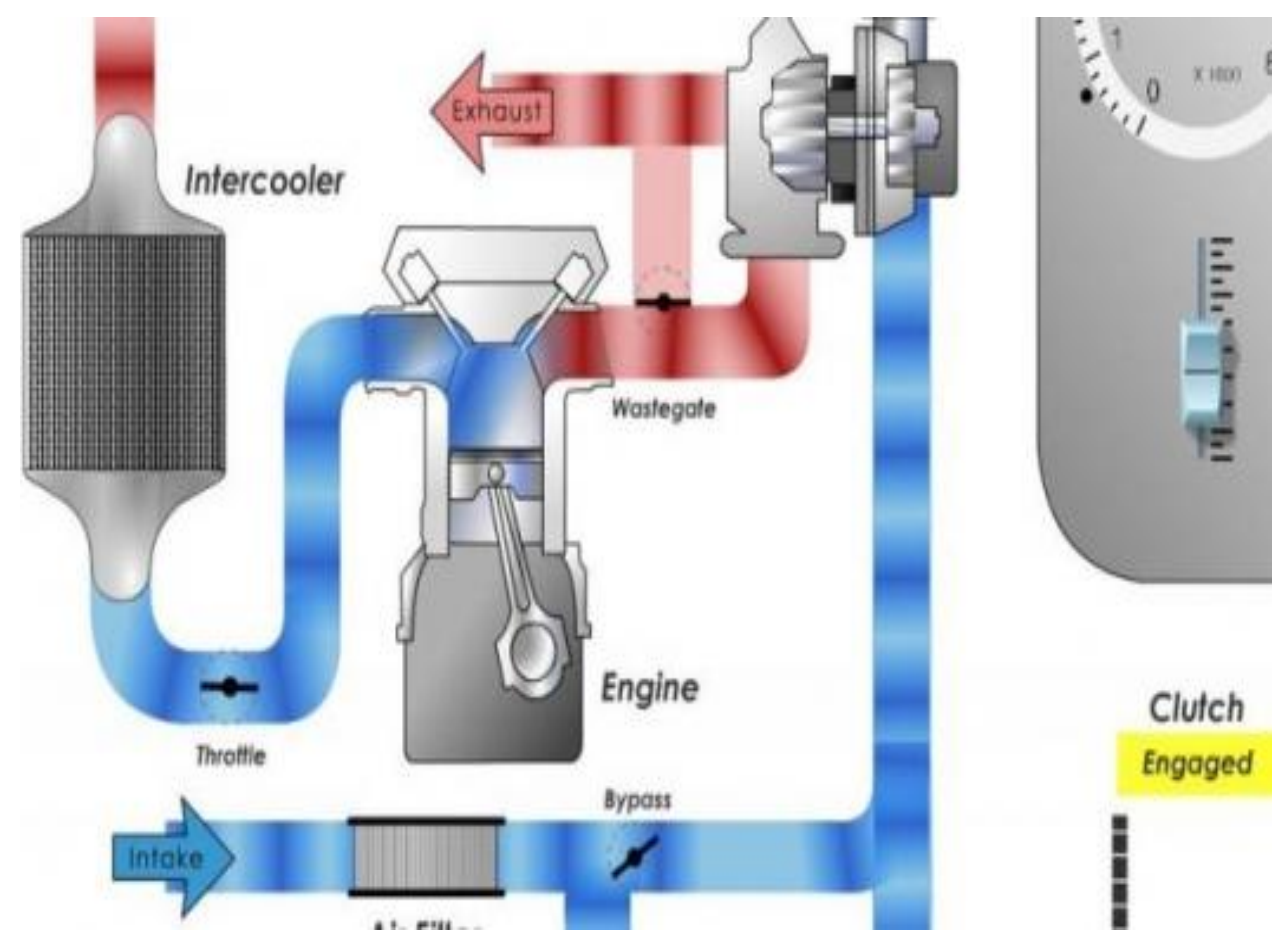

\section{CONCLUSION}

An attempt has been made in this paper, the exhaust gas is used to rotate the turbine and then it is further worked with supercharger and turbocharger. Nowdays it is good with applications of new technology regard to economic considerations and engine efficiency.

\section{REFERENCES}

[1] Mohd Muqeem ,Dr. Manoj Kumar "TURBOCHARGING OF IC ENGINE: A REVIEW ", INTERNATIONAL JOURNAL OF MECHANICAL ENGINEERING AND TECHNOLOGY (IJMET) Volume 4, Issue 1, January- February (2013), pp. 142-149.@ IAEME

[2] S.Sunil Kumar Reddy, Dr. V. Pandurangadu, S.P.Akbar Hussain " Effect of Turbo charging On Volumetric Efficiency in an Insulated Di Diesel Engine For Improved Performance" International Journal of Modern Engineering Research (IJMER) Vol.3, Issue.2, March-April. 2013 pp-674-677.

[3] AMALORPAVA DASS. J, Mr.SANKARLAL "Fabrication And Implementation Of Turbo Charger In Two-Wheeler" International Journal Of Computational Engineering Research Vol.3Issue.3.

[4] S. Vanangamudi, S. Prabhakar, C. Thamotharan and R. Anbazhagan "Turbo Charger in Two Wheeler Engine" Middle-East Journal of Scientific Research 20 (12): 1841-1847, 2014 ISSN 1990-9233 IDOSI Publications, 2014.

[5] Donepudi JAGADISH, Puli RAVI KUMAR, and K. Madhu MURTHY "THE EFFECT OF SUPERCHARGING ON PERFORMANCE AND EMISSION CHARACTERISTICS OF
COMPRESION IGNITION ENGINE WITH DIESEL-ETHANOL-ESTER BLENDS" THERMAL SCIENCE, Year 2011, Vol. 15, No. 4, pp. 1165-1174.

[6] José Ramón Serrano, Pablo Olmeda, Andrés Tiseira, Luis Miguel García-Cuevas , Alain Lefebvre "Theoretical and experimental study of mechanical losses in automotive turbochargers" Science DirectRenewable Energy 34 (2009) 989-993 .

[7] Murat Karabektas "The effects of turbocharger on the performance and exhaust emissions of a diesel engine fuelled with biodiesel" at Science Direct Renewable Energy 34 (2009) 989-993

\section{BIOGRAPHIES}

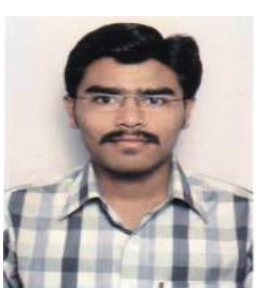

Prashant N. Pakale. Student-M.E. (Mechanical), Mechanical Engineering Department, D.N.Patel College of Engineering, Shahada-425409 Maharashtra, India Emailprashantpakale34@gmail.com

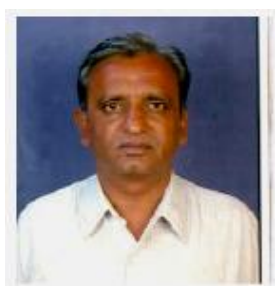

Prof. S. U. Patel H.O.D. Mechanical Engineering Department, D.N.Patel College of Engineering, Shahada425409 Maharashtra, India. Emailsupatel2004@rediffmail.com 